[ This is the Author's Original Manuscript for this article. It is pre-review. The Version of Record of this manuscript has been published and is available in Cultural Studies 32(1), 2018, https://www.tandfonline.com/doi/abs/10.1080/09502386.2 017.1394340 ]

\title{
On being affected: feeling in the folding of multiple catastrophes
}

\section{Andrew Murphie}

\section{Email}

a.murphie@unsw.edu.au

ORCID ID

0000-0002-1593-4151

\author{
Postal Address \\ UNSW Sydney \\ c/- School of Media and the Arts, \\ UNSW Sydney, 2052 \\ Sydney, Australia
}

\begin{abstract}
How possible is it for a life of ongoing feeling to hold, given the world's current becomings? Much of this article will consider three of the most pervasive of the current disruptions as disruptions of living and feeling: climate change, social change, and, in more detail, what I will call a 'third media revolution'. All three of these disruptions (and many others) are themselves multiple. They all fold through each other. Living and feeling thus find themselves in the midst of catastrophic multiplicity. This catastrophic multiplicity haunts much of what's going on. Questions concerning what can be felt within this folding of catastrophes into each other are important contemporary questions. Feeling itself-what it is, what it does, and what the future of feeling might be-has become both a field of struggle, and a complex and open-ended question. A secondary set of questions here will concern the future of studies in relation to these questions of living and feeling - of Cultural Studies, Media Studies, disciplinarity in general, and finally 'study', as discussed by Fred Moten and Stefano Harney (2013).
\end{abstract}


Keywords: Affect, Climate Change, Media Studies, Digital and Networked Media, Cultural Studies, Catastrophe

Funding: This work was supported by a Canadian Social Sciences and Humanities Reseach Council Partnership Grant: Immediations; Art, Media and Event.

Biographical Note: Andrew Murphie is Associate Professor of Media and Communications at UNSW Sydney and Editor of the Fibreculture Journal and Fibreculture Book Series, both with Open Humanities Press. He writes at the junction of media, philosophy and social organisation. 


\title{
On being affected: feeling in the folding of multiple catastrophes
}

\author{
Andrew Murphie
}

Relation is not lived absolutely (it would deny itself), it is felt in reality. (Édouard Glissant 2010: 17)

Changing changes. (Brian Massumi, 2002: 10)

\section{On Being Affected ${ }^{1}$}

Despite everything, the questions remain those of life, or better, of feeling as the ongoing coming together, or falling apart of life. Yet how possible is it for a life of ongoing feeling to hold, given the world's current becomings? Much of this article will consider three of the most pervasive of the current disruptions of living and feeling: climate change, social change, and, in more detail, what I will call-without any great claim to originality-a 'third media revolution'2. All three of these disruptions (and many others) are themselves multiple. They all fold through each other. Living and feeling thus find themselves in the midst of catastrophic multiplicity.

This catastrophic multiplicity haunts much of what's going on. It is felt and thought with intensity, yet, in that it is not easily accommodated to given habits of feeling, remains unfelt and unthought. It is perhaps currently both

\footnotetext{
${ }^{1}$ I am grateful to be part of an SSHRC funded project Immediations that has allowed the development of this work. Thanks also to Sarah Cefai for her limitless patience and encouragement and to Greg Seigworth and Lone Bertelsen for editorial advice. As always, no one else is to blame for the many flaws herein.

${ }^{2}$ For example, see McKenzie Wark's discussion of 'third nature', vectoralist capital, abstraction and hacking, from Virtual Geography (1994) to his more recent work, and Molecular Red (2015), on new thinking on technology and climate. Just some of the other important thinkers here for me are Donna Haraway, Matteo Pasquinelli, TizianaTerranova, Luciana Parisi, Jussi Parikka, Massumi, Michel Bauwens' work on P2P culture, Erin Manning, Jennifer Gabrys, Yuk Hui, Ned Rossiter, Anna Munster, Adrian Mackenzie, Bodil Marie Stavning Thomsen, Alanna Thain, Søren Pold, Geoff Cox, Olga Goriunova, Matthew Fuller, Lisa Parks, Wendy Chun, Tung-Hui Hu, Dan Mellamphy and Biswas Mellamphy. Jennifer Daryl Slack writes that 'liberated from the need to he any one thing, communication gives us permission to look long and hard at the world in order to explore how it works and ... propose changes to make it better' (2006: 223). The precursors of the third media revolution would include the cyberneticists as a whole, not only Wiener but Bateson, and also the like of Whitehead (see Murphie, 2017).
} 
these, intensely, at the same time-unavoidable and unable to be felt and thought with any clarity or adequacy to contemporary events. Questions concerning what can be felt within this folding of catastrophes into each other, and of how or even whether this can be felt, are therefore some of the most important contemporary questions asked of life. It is no wonder that feeling itself-what it is, what it does, and what the future of feeling might be-has become both a field of struggle, and a complex and openended question. Is our thinking-feeling (Massumi 2008) of feeling itself adequate to answering such questions-not only in the academy, but in living (not that they are always separate)? Do our habits of affecting and being affected give us, or the world, what is needed? Do these habits allow us to take on not only the like of climate change, media change, and social change, but also a more general catastrophic multiplicity in which they are interwoven? A secondary set of questions here will concern the future of studies in relation to these questions of living and feeling. These questions concern Cultural Studies, Media Studies, disciplinarity in general, and finally 'study', as discussed by Fred Moten and Stefano Harney (2013). The essay is an attempt at formulating a set of problems rather than solving them.

\section{Values, Defensive Propositional Feelings and Thresholds}

Questions of value arise quickly within catastrophic multiplicity. The stress of catastrophic multiplicity is a fertile ungrounding in which many previous social and political problems become repotentialised and mutate. Can the values inherent to living survive this? Can the values inherent to living even be thought, or felt? Or, to approach this from another angle. do values remain the same? As life becomes subject to more intense change, so do the values that make life liveable. Value needs to become paradoxical to endure. It needs both to hold in a general sense (as in holding living together) and to change with change. Furthemore, it needs to do both these not only in and through every instance of a life's actuality, but with regard to living's tendencies and potentials, and each life's unique infinities (Massumi 2017).

Such questions also concern habit's relation to value. Is it possible to break out of the habits of feeling that make a life, when these habits of feeling hold it back, stuck in outmoded ways of living? A felt life can be destructive. Aspects of value and habits of feeling can constitute themselves through fundamental injustices. Or, from a very different perspective, other aspects simply no longer fit what's going on. What kinds of collectivities of feeling more easily go with change, even with a catastrophic multiplicity of change, breaking out of the defence of habits of feeling, of living? How does one break out of one's own defence or break free of the defences of others to which one is subject, or, commonly, both? Some defences often seem to make sense in terms of basic affective survival. Yet others are often defences of what seems simply indefensible. Indeed the danger in the midst of catastrophic multiplicity is that every 
kind of defence finds renewed strength at exactly the wrong moment, in a kind of catastrophic multiplicity of reactionary feeling. Part of this assembles a constellation of defensive propositional feelings (propositional feelings being 'lure[s] to creative emergence in the . . future' [Whitehead, 1978: 263]). Defence itself becomes proposed as a contemporary key to so much of what Alfred North Whitehead called the 'lure for feeling' leading into the future. The assemblage of defensive propositional feelings becomes powerful if increasingly phantasmagoric and desperate. These feelings propose that certain ways of life are the ways of life and must be defended, even and especially against reality itself.

The defensive propositional feelings create their own multiplicity, in part in a snarl with catastrophic multiplicity. They are always in a complex tangle of differential relations: to each other; to happier propositional feelings concerning life; to degrees of acquiescence- from the outright belligerence toward any alternative, to ironic acceptance ("I know but ...") or simply the resigned; and to the micropolitics of multiple real goings on in every instance of living ${ }^{3}$. Many of these destructive propositional feelings are well known (although better considered as propositions than absolutes, which is not at all to deny their very real effects-the case is the opposite). Some of these are found in: the supposed supremacy of white life; settler-colonial life; an assumption of life as preferably "neurotypical"4; the life laid out for all by the 'Capitalocene' (Moore 2015; Haraway 2016); patriarchal life; the insistence on normative gender identification and heterosexuality, or the insistence on a series of identifications (or sometimes non-identifications) of all kinds, often in particular combinations; ableism; the peculiar contemporary character of American exceptionalism and nationalism in general; a persistent human exceptionalism with many variations; and intergenerational inequity. At the same time, the compilation of propositions on such a "list" is both completely necessary and unsatisfactory. It is necessary because these kinds of defensive propositional feelings literally target the series of more productive socialities and the affirmative propositional feelings and values via which real life is lived by many. For Whitehead a proposition does not have to be true to be a lure for feeling and thus to play its part in living, thinking and feeling. On the other hand, no matter how important, any list

\footnotetext{
${ }^{3}$ For one thing, as Elizabeth Povinelli notes, 'Nor do I think that all forms of antagonism are equivalent .... at the level of socio-material organization and process class difference is not equivalent to settler colonial difference is not equivalent to gender difference is not equivalent to racialized difference no matter that we use the term "difference" in each case' (Povinelli, Coleman and Yusoff, 2016).

${ }^{4}$ As Erin Manning notes, acknowledging that things are different for the "neurodiverse", '[d]espite its role as a founding gesture of humanism, of individualism, neurotypicality remains for the most part in the background of our everyday lives ... so we underestimate both its force and its pervasiveness' (2016: 3).
} 
will be unsatisfactory because it misses the ongoing creativity of what is effectively a social machine for destructive propositional feelings-macro and micro. There is a constant production of variations within and between these defensive propositional feelings, and of many more that lie beyond them. It is also true, however, that no list could contain the creativity of a more affirmative, 'minor' sociality, or the creativity of this sociality's propositional feelings, values and lived life.

This begins to sketch a broad social condition that needs to be considered in its entangling with catastrophic multiplicity. This social condition involves a series of unresolved tensions between very different values, identities or the many variations on the lack or pliability thereof, and propositional feelings. It also involves variation within all of this, even and especially within and between the supposed non-variables, especially as this condition meets the more immanent feeling of power in any given situation. The broad condition and its immanent variation are at the heart of the machine for defensive propositional feelings, the diverse minor socialities of affirmation, and the relations within and between these. All of these are actively-if very differently from different "sides"-fuelled by an ongoing and again highly creative and adaptable normalization/denormalization of increased injustice in which propositional feelings play a key role. Any side of this can be strident in whatever degree of denial it can muster of catastrophic multiplicity, including increasingly obviously ecological catastophe; even as the catastrophic easily engulfs whatever such defences or even at times affirmative socialities can throw at it. The many permutations of this whole constellation are increasingly central to feeling, and to the ongoing conversion of general feeling into propositional feelings for defence and/or affirmative sociality. How can we create/conserve a life of feeling that is more (and less) than the defensive; one that affirms the affirmative, draws out 'the human differential within the general ecology' (Moten $2015 b^{5}$ ), and does this in the face of contemporary events? What work of feeling allows life to emerge once again from what Fred Moten calls simply a modernity that 'is an ecological disaster' (two of the pillars of which have been slavery and settler-colonialism) (2015a)?

Thought carefully across different modes of "life", all these questions imply each other. The issue raised across them all is indeed feeling-in all its multiplicity-as the ongoing constitution of life as lived (which I will take as provisional definition of feeling for this essay). This is not only a question of lives (although these are most certainly at issue). It also concerns each instance of collective living-as a complex of lived feeling, in a life's actualities, its tendencies, and its potential. Each collectivity of feeling has its own unique attachments to limited infinities of engagement. Each collective life is made and made again within its own negotiated

\footnotetext{
${ }^{5}$ Moten is here discussing 'black social life' as such a life.
} 
avoidances or crossings of thresholds. Brian Massumi writes that these thresholds are important to collective, felt life because-

When a threshold is crossed into a new relational field, everything re-jigs, what is valued in life changes, life is revalued. Deleuze and Guattari say that there is an intuitive collective understanding of where the limits are for a given field. Not going past the limits, avoiding tumbling over into a new field, is a marker of people's collective, affective investment, their differential attunement, towards staying in the relational field they're in, not because of how much they get per se, but because of the life-values, the quality of life, that this relational field affords them. (2015b: 138)

Yet neither attunement, nor avoidances, nor crossings are so easy from within the contemporary catastrophic multiplicity. Apart from defence, lifevalues, established or new, do not so easily take. Feelings-even especially strong and perhaps unfamiliar feelings-are in many ways not so comfortably felt, if in some circumstances they can be felt at all. Yet neither does a comfortable felt life always hold. For one thing, as so much valuable work on affect suggests, life now is necessarily lived across lives, a felt life of extreme incompossibilities, requiring very different attunements across different relational fields (even between reactionary and more affirmative life as lived). Thresholds and limits and infinities multiply in tension everywhere, to the point that being affected by and affecting the world in any easy way seems a nostalgic and impossible dream.

In response to this, many social systems become even more reactively attuned to neurotypical fantasy (many universities, at least in Australia and the UK, are exemplary in this respect and it is in this fantasy that Cultural and Media Studies increasingly have to situate their teaching and research). An all too common enhanced cultural cognitivism, in many guises, is repotentialised in the defence of a normalizing rationality (although what is actually the norm of this rationality shifts constantly with the one consistency that the advantage usually lands on those in power). A rationalisation and systematisation of representations of every kind is ongoing (Murphie 2014). Everything that is solid may melt into air in the contemporary catastrophic multiplicity, but this air is then sucked down and broken down into systematised elements, and organised into a relatively lifeless life, via metaphors drawing on 1950s computation (which in reality have as uneasy a relation to actual recent computation as as they to do to actual brains or minds) (Dupuy 2000). Thinking, the social, social and political interests, and even catastrophic multiplicity, are brought into a multi-scalar circulation of measure, modulation and adjustment. Feeling is only fleetingly acknowledged within these neurotypical systems, preferably in a pre-cognitivized form, and certainly not as the ongoing constitution of life as lived. Yet the life lived with these systems is drenched through and through with what is-systematically at least- 
largely unacknowledged feeling. Feeling leaks in and out at every point. Much of work-by "the system" or by those who must work with it-deals with the mismatch involved (DeJours 2007). The farthest reactionary limit of this kind of system in terms of life lived is something like the end of Kubrick's Dr Strangelove, which even in 1964 so accurately depicted the fate of defensive propositional feelings married to a normalizing rationality.

It is impossible not to be involved in some way with the very real cultural tangle this produces. Yet repotentialising cultural cognitivism in its contemporary mode only gets in the way of a deeper involvement with catastrophic multiplicity. One problem here is perhaps that of beginning with a badly formed concept of decision-one largely divorced from feeling, or in which feeling is reduced to a subsidiary to the larger rationalist system (a related problem is that of selection in decision, that decision must always choose one path or another-the event-field is lost to decision with every selection). Feeling becomes low level reward, a being grasped and affirmed by the system. The attempt is to reduce the feeling that counts and is counted to the limited thinking-feeling involved in (the rapidly fading phantasy of) conscious choice within a simple, preestablished set of parameters.

Decisions currently being made in response to catastrophic multiplicity have very little to do with this, and serve a need to have very little to do with this. Cognitivism simply canot grasp what is going on (and "grasp"6 very precisely describes one way of understanding feeling in process). Catastrophic multiplicity not only challenges this limitation and reduction of feeling, but raises the much more fundamental question of what feeling really is, or could be, and whether different aspects of feeling, thought in all its multiplicity, can still feel with each other so that world can hold. Catastrophic multiplicity is itself a complex storm of feeling, of aspects of world feeling each other in intense, unexpected and constantly mutating ways ways. For example, in climate change carbon dioxide emissions can be understood as agents of feeling, felt transformatively by the world at large, transforming not only the world but what it is to feel in the world in many ways (heat, obviously, but also entire felt modes of living, for humans or other creatures). Or consider the way that sensors and algorithms and data-which I will point out shortly Whitehead called 'potentials for feeling' (1978: 88)-are able to bring together a very different world of nonhuman feeling which again transforms what it is to feel in the world. The processes of feeling that inhabit these events-

\footnotetext{
${ }^{6}$ For Guattari, 'grasping' comes from a reading of Whitehead's 'concrescence', which is the coming together of what are for Whitehead the basic actual occasions of process (see Bains, 2002: 103). Grasping for Guattari is a kind of ongoing bringing together that oscillates between embodied 'finitude' and incorporeal infinitude. Grasping brings together diverse aspects of process (including the chaotic, the asignifying, etc). It allows, indeed guarantees, a 'possible recharging with processual complexity' (Guattari, 1995: 55).
} 
human and nonhuman-come together in unexpected ways and fall apart in others.

A reconsideration of decision-one that works with or even as feeling in the event-might help. Indeed, within life as lived now there is tension regarding both decision, and about the field in which decisions are made. If this is not a field of smooth process, or at most a dialectical antagonism between relatively smooth processes-female/male, science/humanities, Hayek/Keynes-then what is this field? There are tensions about the field in which decision is to be located: is it within the 'dimensionless place' critiqued by Glissant (2010:1), or the brain, the body, the nonhuman, or social relations? There are tensions as to whether decision is conscious or not, and which of these, and to what extent, for whom, and indeed whether such a thing as conscious decision even exists. There are ongoing tensions about the relation between the thought and/or felt (and who is quite literally counted and in what way via the distribution of the thought and the felt [Da Silva, 2007]). All of these tensions begin with a split between a world, a field, or a system, and individual moments of decision within this. To have access to these moments, or to appear to, which might amount to the same thing, is to have power in this constellation-both in terms of capability and domination. Yet this split between decider and world involves what Whitehead called a problematic 'bifurcation of nature' (between nature apprended-decided-and nature apprehendingdeciding) (Whitehead 1920: 26ff).

There is another way to think decision, however, that provides a way out of both cultural cognitivism and the larger problem of the bifurcation of nature that underpins it. It also addresses the feeling within decision. It begins with the understanding that the field and the decision are not split. The field is not a more passive context for more active decisions. Rather, as Erin Manning suggests, the decisions that always matter most are those decisions in which a field/event itself expresses a 'decisional force'. This force 'carries the more-than of the anarchic' (2016: 33) and 'tweaks' the field/event 'toward the punctual creation of life-living' (88). Each worldsmall or large-decisions, as this world. Decision in this sense also means the gathering of feeling from within a world to make the next world, with its new constellation of feeling. Decision in this light is a kind of collective differential movement of all the participating movements in events. It is a world's multiplicity in movement (along with this world's being affected and affecting). Manning thus considers movement, which is living and feeling in process, as also 'decisional', though not 'volitional'. In all this, decision is considered 'not as external to event but as the cut, in the event, through which new ecologies, new fields of relation are crafted'. Manning also suggests that even '[n]on-conscious movement is decisional in the sense that it is capable of altering the course of the event in the event'. (2016: 19). Manning calls this "decisioning" an attuning to the event on the part of movements within that event. 
Manning gives the example of the way the movements of dancers and athletes (a 'soccer player') decision fields/events from within them.

The talent ascribed to the soccer player is ultimately due not to her volitional ability to move, but to her capacity to effect cause in the event, opening the field to its potential through intuitive realignings activated by mobile cues, leading to a (re)directing of the game. (18)

Dealing with catastrophic multiplicity requires exactly this kind of 'capacity to effect cause in the event'. Of course catastrophic multiplicity is not a game of soccer. Although, as in soccer, any movement within the events involved can also be described as a kind of 'fielding' (Manning, 2016). Fieldings 'are before all else a tuning of affective tonality' (217). Fielding and feeling are therefore closely related-the fielding is the field's attuning to felt contrasts or intensities as they move (as feeling). In fielding different aspects of feeling can come together into working, felt contrastsintensities that hold in the moment (movement of the ball, of players, the state of the pitch, wind and rain, changes in muscle tension and breathing; extreme weather events intertwined with economic recession and algorithmic culture). Fieldings 'field' in that the 'potential of a field cannot be understood apart from what it does, from what it can do, in relation to the fielding it co-activates' (119). Manning mentions gravity here as an example. The movement of the wind with a forest fire might be another example. Or the way that a community forms, in the moment, on the streets, or in a protection effort against fossil fuel corporation infrastructure such as an oil pipeline. Or the way new concatenations of AI, networks and relations of production "decision". Or the very many fieldings that come together in climate change. Manning calls the thinking appropriate to fielding 'choreographic thinking, emphasizing the ability of movement to cue and align in spacetimes of composition in ways that open experience to new registers' (19). This provides a way into choreographically thinking and feeling catastrophic multiplicity. Yet in catastrophic multiplicity the new registers-and challenges for collective life-are somewhat extreme.

It is how to attune to, to move with, and to field and feel the current complexity of events, in the midst of catstrophic multiplicities, that are at issue here. There are many movements, human and not and in-between, that decision together in this sense from within the events of catastophic multiplicity.

\section{Climate change and everyday denial}

Global levels of carbon dioxide in the atmosphere have now passed 400 parts per million, climatic records are being broken at an accelerating pace, and scientists seem to be constantly discovering more possible tipping points and likely nonlinear climate change events. Climate deniers and fossil fuel lovers have taken over many governments. We are hurtling towards an unliveable world much sooner that we might have thought a 
few years ago (for some this world has already well and truly arrived). Yet despite this, Alice Bell suggests that we remain climate change deniers. By this she means that we attune to the fielding of climate change primarily through an 'everyday denial'. We are unwilling to negotiate the thresholds involved.

In many ways this everyday denial is understandable. Climate change is abstract. We only know about it through vast, complex, global and multi-generational networks of interdisciplinary, highly advanced science. It's easy for it to drop out of our minds, even if we believe in it.

On the other hand:

It's also very scary. A friend who, once upon a time, was the greenest person I knew, hugs her infant son tight and tells me softly, slowly: 'I just can't think about climate change since I had him.' This feels entirely rational to me.

This abstraction ${ }^{7}$ and scariness is only one of a vast number of ways in which climate change comes together in feeling.

Climate change is a catastrophe of feeling. As a catastrophic multiplicity in itself and in relation to other catastrophic multiplicities, it is a highly complex fielding of events of both human and nonhuman feeling. As such, it probably too easily bracketed under a single label (practically speaking, in a wiser world we might already have broken the problem up into more readily dealt-with problems). In addition to its complexity at any given moment, it changes constantly. It differentiates rapidly over time (becoming something else), and just as rapidly brings together new intensities in integrals of differential relations. The shifting differentials/integrals involved act as intensifiers of influence or feeling. There is an intensive dissolve between events in the world formally known as nature, industry, politics, media and communications, the history of many sciences, and, simply, everyday life. This makes [climate change] a 'wicked problem' (Incropera 2015), one in which enhanced feeling breaks threholds of every kind (sometimes leading to a paradoxical numbness of feeling in humans due to overwhelm, the unfamiliarity of feeling and the inability to field such feelings in any coherent way).

Yet as I have begun to suggest, climate change is not the only immense change confronting the world. Indeed, there are now multiple ends of the world beckoning. There are catastrophes major, such as: literal ends of the

\footnotetext{
${ }^{7}$ Abstraction itself is arguably a general condition of feeling, for example in thought as feeling, as 'thinking-feeling' (Massumi 2008) across events, as those events' contrasts, or indeed as contrasts/intensities in general. Abstraction has specific and shifting constitutions through time-or, time is constituted as an abstraction of the foldings of fieldings.
} 
world via various means from climate change to the vicious triumph/collapse of capital; or the collapse of democracy and rise of micro and macro fascisms and neofeudalisms. The are also related catastrophes minor (one might be the end of some academic disciplines of which we are fond). Indeed there's a competition between catastrophes at all levels that is ripe for the market to exploit (Klein, 2007). And it is exploiting these catastrophes (Enclaves anyone? Offsets for your lifestyle? Hedges against the decline of coal? Restructure your university with the help of consultants perhaps?). Thus rampant exploitation becomes another aspect of catastrophic multiplicity. It is certainly tempting to deny much of this, to look away and just live your life/do your work, or buy (literally) into the marketisation of these multiple ends. There seems a cultural infinity now of available defensive propositional feelings (another aspect of market/system that exploits these events). It is no wonder that catastrophic multiplicity is 'scary'. It seems pitched against the possibility of thought in any regular sense, with destructive modes of life too often decisioning current events. All sides of this are complicated by the aspect of catastrophic multiplicity that I am calling here "the third media revolution".

\section{The Third Media Revolution}

In 1929, Whitehead suggested that data was 'potentials for feeling' (1978: 88). Among other things, Whitehead was of course a philosopher of mathematics, and a key figure in the history of symbolic logic and therefore the history of the computing to come. Yet his work of 1929 only edges into the material revolution in computing that began in the 1930s. It certainly came before the cognitivist developments of the 1950s that aligned a notion of computing as symbolic processing with the function of the human brain, thought, and psyche (in that order). Perhaps it was this earlier moment in history that allowed Whitehead to conceive of the world as feeling in process and data as potential for feeling within the ongoing process of the world. By data as potential for feeling, Whitehead means any kind of data, for example sunlight, or a mood swing. Mathematical or computation data are just instances of the general principle. One could consider all data as gathering and gathered through a kind of networked feeling out, in the grasping and modulation of fields.

The third media revolution pivots on the understanding of data as potentials for feeling - feeling here as any kind of fielding or attunement within, or grasping and forming of, worlds (this includes emotional life but far exceeds it). Like Whitehead, the third media revolution think and works with all kinds of data. This includes computational data but also every other aspect of world (human and nonhuman) as data. In the third media revolution's generative movements, sensors, computational data and algorithms feel out other sensors, computational data and algorithms. Yet this is also a feeling or fielding with the world at large. The third media revolution has partly cognitivist origins. There is an ongoing sweep of cognitivism within it, and it often expresses itself with a cognitivist 
discourse. Yet the intrusion of the third media revolution into so much more of the world than before, and the power of its move far beyond the usual domains of media and communications, cannot be understood without understanding data as potentials for feeling, and often for feeling very differently.

Simply put, the third media revolution is a crossing of thresholds brought about by contemporary, pervasive media and communications change. By this, I do not mean the way that computing, networking and the like of social and mobile media have changed media and communications over the past 30 years. Despite the disruption, media and communications have until now still felt like the media and communications we more or less know. We still make phone calls, write letters (if as texts etc), make images and show them to other people, watch films and tv, if in different formats and settings, and often via different platforms. Indeed, in some ways much of new media take up has involved a significant intensification of old media (no doubt in tune with McLuhan's dictum regarding the content of new media being the old).

Much more than this is involved in the third media revolution. Like climate change, this seems indeed immense and pervasive, abstract, and unfamiliar, not easily attuned with. It is also extensive, affecting life profoundly. Yet it is also highly technical and the province of experts. It has obvious impacts. Yet much of it is imperceptible. It is also scary. Just one aspect of this is that it threatens to change the basis of the economy, transforming the relation between labour, capital and production via the automation provided by hypernetworks of sensors and more, robotics, artificial intelligence and machine learning. It is even more fundamentally changing the basis of relations between media, world and modes of living. A new multiplicity of powers comes into being between media and world, with new fieldings, new feelings, new ways of sensing and grasping events, and new decisional forces. These new powers increasingly often seem to be by-passing familiar powers, relations and feelings of modes of living.

This third media revolution seems to me to be as large as the first two media revolutions. All of these overlap a great deal in terms of their particular tendencies and developments (and none of them disappear). However, they all reach particular thresholds, differently at different times and in different places, at which it is possible to point to dramatic change.

A familiar sketch might suggest that the first of these media revolutions involved the development of forms of expression more open to abstraction, that is, the invention of writing. Writing famously disrupted oral culture, changing memory, thinking, communication and the sense of self and community in the process. It fostered the keeping of records and accounts, and thus capital as possible abstraction from immediate circumstance. In all of this and more feeling was reconstituted. The first media revolution 
also enabled the possibility of a much more extensive first enclosure-that of land, or humans for that matter (in slavery), as traded property. The second media revolution involved the invention of new forms of reproduction and representation, and the distribution of reproduction and representations-think the printing press, photography, telegraphy, film, and yes, from this perspective, computing (although the latter creates the possibility for the third media revolution). As Elizabeth Eisenstein writes of the printing press, the second media revolution was an 'agent of change' (1979). It famously fostered a scientific revolution, democracy, colonisation, religious change, the formation of publics and ground-laying for the power of nation-states, along with modernity and the enlightenment. Again, there is a reconstitution of feeling. The second media revolution also enables a second enclosure, that of intellectual property. Much of the recent intensification of media and communications in so-called "new", social and mobile media fits here.

It is hard to underestimate the profound nature of world changing performed via these first two media revolutions. The third media revolution, like the first two, changes general and specific worlds dramatically. It requires us to think mediation and communication differently. It again reconsitutes the basis of much of fielding and feeling, although we do not really completely know how as yet. Media and communications become much more obviously entwined with the relational fieldings and feelings in which media and world meet and reform. New kinds of forces form, along with new kinds of feeling-human and more crucially nonhuman (and 'more than human' [Manning 2013]). This allows a massive intensification of what media and communications do in the world, in part via a dramatic increase in the power, reach, and the complexity of autoadaptation to worlds of media and communications. At the same time, there is an ongoing, in-situ auto-creation of variations on world. More generally, the potential for a 'becoming-environmental' of power (Massumi 2015a: 23) arises because the third media revolution enables a vast increase in both the ubiquity and autonomy of media and communications. Everything can be felt and relayed. This allows ithe third media revolution to both automate and intelligently modulate worlds, not only in connection with "us", but with more aspects of world without us. There is an ongoing convolution (or infolding) of signal and signs, of passage and passaged, in something like a series of Fourier [signal wave] transforms. This is applied to more of the world/life/feeling from within much more of the world/life/feeling. This provides what are simultaneously dramatic extensions and diminutions of 'human' powers, along with an uneven extension of 'non-human' powers. The result is often a local diminution of powers for many individual communities and modes of living. In sum, the third media revolution involves a new and much larger series of collisions between media and worlds (in every sense of the word "world", macro or micro). Thus it enables a 'third enclosure', which is simply put that of everything that has not already been enclosed (Murphie 2011). 
The third media revolution has two very different accents. At best these form a productive contrast that makes possible a deeper engagement with the transitions required by catastrophic multiplicity. Yet this is not always the case. At worst, the contrast threatens both human and nonhuman worlds. On the one hand, as mentioned above, the third media revolution involves a 'becoming-environmental' of power. Media and communications enable much of this, often in collision with existing or alternative worlds. Part of this is a literal extension of media and communications into more of the environment. Yet this has subtler elements in which life, worlds and fieldings/feeling are fine-tuned to power. Massumi suggests that in 'the ecology of powers' the becomingenvironmental of power involves 'over-all, environmental control (the power to modulate emergence immanently to the field of life)' (2015a: 235). It deals in 'preemptive control' (200). 'Rather than empirically manipulate an object (of which it actually has none), it modulates felt qualities infusing a life-environment' (200). The becoming-environmental of power, that-

... returns to life's unlivable conditions of emergence in order to bring life back, redirecting its incipience to alter-emergent effect, is an ontopower. Ontopowers rejoin naturing nature's force of emergence, in order to ride it out, and even hijack it. (41)

This is an active parasitical hijacking of worlds. In media and communications terms, think drones or the internet of things, or artificial intelligence or data analytics' colonisation, pre-emption, or even outmoding of human thinking-feeling.

All this challenges the other accent of the third media revolution, which involves a changing concept of world itself, and thus of thinking, feeling, communication and much else. In this accent the third media revolution speaks of (and listens to) a world already and always in process, always already 'a medium' for the 'vector transmission of influences', or simply the movement of feeling (Whitehead 1978: 286; see also Murphie 2017). Wolves are found to have dialects when howling. Plants have many means of communication, feeling and sociality, including via networks of mycelia (fungus threads) under the ground. More than this, every event, as world in process, involves the transmission and gathering of influences or feelings via the world as medium. This is the more "ecological" voice of the third media revolution. It gives expression to the possibility of a more careful revolution in thinking-feeling. Think Bateson's ecology of mind as siding with the world as medium taken as more positive ecological affirmation. Although this is complicated by the fact that Bateson's ecology of mind is also part of the cybernetic realisation, the general abstraction of complex feedback as fielding. This ecological realisation also makes the becoming-environmental of power more thinkable, the more felt as tendency, and therefore possible. 
The technical elements of the third media revolution, which is thresholding now, are numerous. They evolve quickly ${ }^{8}$. They diverge as much as they converge. Key now are artificial intelligence and machine learning, bots and the general automation of skill and expertise of all kinds (including for example the use of bots in political communication). AI itself now fields, feels and "decisions" in its own co-extensive attunements within financial, business and work or other fields. Then there are voice and facial recognition (and functional automated responses to the like of voice control, gesture or monitored body movement), and automatic translation. An example is machine learning discovering and analysing the wolf dialects mentioned above. Another is the kind of language processing found in Amazon's digital assistant Alexa that scientists currently claim is allowing some form of communication with body cells. All this colonises and undermines the basics of communication. There are also the internet of things, drone networks, and other forms of hypernetworking extending out into the world (the climate science research networks, from to lab to computer modeling, are an early example-Paul N. Edwards [2011] calls this a 'vast machine'). There are robotics and the general automation of physical processes, usually in league with other forms of automation and usually enabled by networked communicational environments of some kind. Again, automation in the third media revolution means nonhuman/more than human (Manning 2013) "decisioning", or "fielding" from within an event. It is also more than human in that what we call "automation" in this sense is both a logical extension from and an eventual substitute for the more reductive and basic forms of automation found in the simpler bureaucratic control of human work, living, thinking and feeling (discussed as cultural cogitivism earlier). The intensifying of this in much of management for many years-and here university management can be exemplary-is in many ways a precursor to the third media revolution. Another aspect of the third media revolution includes virtual, augmented and mixed realities, holograms and new sensate access to the previously imperceptible. These involve a general augmentation and transformation of sensation and perception. Recently it was claimed for example that quantum computing allows magnetic resonance imaging of chemical reactions at the level of atoms-in real-time. Then there are highly developed forms of surveillance/sousveillance which transform the constitution of feeling as public/private, and challenge given understandings of the "I" and the "we". There are electronic and algorithm-based finance, including high frequency trading, blockchain and cryptocurrency (and the more general alt-finance and alt-economics

${ }^{8}$ One simple way to think the third media revolution is that it often involves that which is not easily analysed via the like of "multi-modal analysis", as much of it flips rather quickly and incessantly between the intensely amodal, and the differentially/integrally shifting/combining of modalities (not to mention inventing new modalities, as momentary as these might sometimes be). Many established forms of media and communications (and cultural) analysis, premised on the first or second media revolutions, are inadequate to the third media revolution. 
movements with the potential to redesign important bases of the social). There are not only "big" but generative re-fieldings of data (the latter is simply data as active, moving, dynamic, constantly differentiating/integrating itself). These produce an algorithmic culture, and the like of predictive technics (for example, in "pre-crime" but also of course in the like of climate change planning). From moment to moment, algorithms seem increasingly able to gauge a number of fine tuned, shifting "states" of fielding/feeling, of almost any kind, and auto-adjustrespond to these (from emotions to basic physical changes in the body or collections of bodies, with ramifications for health and medicine, law and governance and much else). There are 3D printing, genetics and the convergence of DNA and media, and the general ability to physically produce reality differently, in multi-scalar and dramatically transformative terms. There is quantum computing that recreates computation itself, qualitatively as well as in terms of pure speed and volume of calculations. Finally, the way that energy grids are becoming "smart", not only via smart meters but via smart grids that decentralise power, is a way that energy is also part of the third media revolution ${ }^{9}$.

Although there are many individual examples of the third media revolution it is also necessary to see it as a complex field(ing) that interweaves other field(ing)s. Again, this transforms feeling. At the heart of these fieldings are complex multipliers and modulations of signal-taken broadly as the transmission of influence or feeling-with constant inversions and convolutions of form and content, of signal and sign, of carriage and carried, all of this extending into world and into other immense changes such as climate and social change. All this gives obvious potential for catastrophe. Finally, the third media revolution, in its collisions of world and media, requires a movement way beyond the traditional province of Media and Communication Studies, or a more traditional Cultural Studies. Media and Communications Studies expand into every field of research, although this questions the discipline as currently formed. The third media revolution's ambition-and its emerging reality-is to become a part of all aspects of world(s), and therefore part of the province of all established disciplines. Established disciplines are therefore left reflecting what are in danger of becoming outmoded constellations of fielding/feeling (although in some cases these outmoded constellations might need protection). This in effect questions disciplinarity itself.

In sum, the third media revolution makes pervasive, complex claims on everyday life, claims that are perhaps, in affective, life-terms, as large as those of climate change. Briohny Doyle's novel The Island will Sink (2016) gives a good account of the combined disruption. The characters are caught up in a hyper-networked world that can supplement memory almost to the point of replacing it. Always networked, any and all experience is recorded and modulated. Most responses to the world

\footnotetext{
${ }^{9}$ Jeremy Rifkin he calls this a "third industrial revolution" (2011).
} 
involve a kind of extreme soft control. Children are so immersed in VR and data networks that any disruption is felt as extreme anxiety (the only time some become emotionally connected to their parents). On the other hand, extreme weather events disrupt all this media entanglement, and the ongoing climate disruption in the like of sea-level rise is constant. This becomes the subject of forms of obsessive and extreme simulations of the experience of fielding catastrophic multiplicity. The main character is a famous immersive director, and specialises in catastrophes, usually environmental. His new work is titled Tsunami.

\section{Social Change}

The third series of pervasive changes that contribute to catastrophic multiplicity to be considered here are social changes. Although there is only the space to sketch what is in any case well known. Once again, the point is that much of this is scary, abstract, and calls for new powers to be affected and affect, in itself, and the more so in combination with the other changes I have described here. Consider both the actualities and, more importantly, the tendencies, the feeling out towards the future, moving through the concurrence of Brexit and the election of Donald Trump and the general failure of the democratic political process. Alongside this though are many exciting new forms of collaboration and cooperation (Iceland's crowdsourcing of its constitution, P2P culture, the Transition movement). So there are forms of democracy collapsing at larger levels but also emerging differently at more local levels. Democracy is now like some weird series of particles coming and going in the Hadron collider. There are also what is truly a multiplicity of resistances to what are intensifications of injustice. Here there is the like of ongoing social movements that are mattering, such as Black Lives Matter, the Revolutionary Love movement, or the many occasions globally in which indigenous people are organising front line resistance to fossil fuel based Capital, as in the Native American nations that gathered at Standing Rock against the Dakota Access Pipeline, a protection event directed against both environmental and cultural destruction. There is also of course the increase of structural and specific violence in increased racism, misogyny, homo and transphobia. This is not to mention intolerance of anything not conforming to the not so much invisible as dead hand of contemporary fossil fuel and property-based Capital. On the other hand, as McKenzie Wark asks, what if this doesn't any more involve Capital as we've thought of it up to now? What if it's something worse (2017)? The hegemonic side of this often involves increasingly well organised (and often legislated) forms of gaming the system and what is effectively legalised corruption, fraud and extortion, within institutions, corporations and governments. This not only allows, but materially supports and provisions attacks on certain lives, and indeed certain entire modes of life. This in turn has allowed the recent series of political moves towards even more extreme governmental/corporate authoritarianism in the US, Europe, Australia, Brazil (and elsewhere). 
As is well known, a series of well-documented shifts in the global balance of economic powers (thus also shifts in the layers of singular economies) underlies this series of social shocks. More than this, however, there is a shift in the very nature of economy. Many such economic shifts involve the crossing of various media/world collision thresholds in for example the way that networked global communications enable transformations in trade and work. These now become entwined with the emerging economic shifts produced by climate change and the challenges of moving from fossil fuels to renewable energy. It is hard to find powers that allow one to be affected by all this without life falling apart, let alone powers to affect it.

\section{Speculation on a Fourth Industrial Revolution}

One way (though not the only way) to describe the way that social change, the third media revolution and even at times climate change come together is in terms of what even The Guardian newspaper is calling the 'fourth industrial revolution' ${ }^{\prime 10}$.

The First Industrial Revolution used water and steam power to mechanize production. The Second used electric power to create mass production. The Third used electronics and information technology to automate production. Now a Fourth Industrial Revolution is building on the Third, the digital revolution that has been occurring since the middle of the last century. It is characterized by a fusion of technologies that is blurring the lines between the physical, digital, and biological spheres. (Schwab, 2016)

The fourth industrial revolution indicates a threshold in which the industrial bases of the social (now extending through world and life) are caught somewhat ambiguously between different if entwined kinds of power. Matteo Pasquinelli describes these variously as 'carbosilicon assemblages and cyberfossil capital'"1 (2016) and 'Augmented Intelligence trauma'. He writes of the latter:

One day, it will not be arbitrary to reframe twentieth century thought and its intelligent machines as a quest for the positive definition of error, abnormality, trauma, and catastrophe-a set of concepts that

\footnotetext{
${ }^{10}$ See https://www.theguardian.com/sustainable-business/series/fourthindustrial-revolution

11 'Energy and Information ... bifurcated out of the industrial machine of the 19th century ... They initiated and extended two technological lineages or machinic phyla: ... the one of energy as a medium of motion and the one of energy as a medium of control and communication, the paradigm of ecology and the one of cybernetics. The two regimes carried of course different energetic costs and also quite different colonial costs ...' (Pasquinelli 2016)
} 
need to be understood in their cognitive, technological and political composition ... (2015: 7)

Arguably that day is already here.

The agony felt (or in some ways unable to be felt in any manageable way) now involves Capital (or 'something worse'" ${ }^{12}$ ) reorganising through both climate change, the third media revolution, and the fourth industrial revolution, even as these intrude further and in more refined ways into world, into us and the very consitution of "us"-whether self or social, into the fielding and feeling of life, and of course into the culture that is the domain in which Cultural Studies moves.

As I have begun to suggest above, the reorganisation of labour is a large part of this. As Tim Dunlop writes, aside 'from climate change, this reinvention of work is the most wicked problem facing humanity, and we can see the unease it causes reflected in the politics surrounding Brexit, and of Donald Trump, Bernie Sanders, Jeremy Corbyn and Pauline Hanson' (Dunlop 2016). Dunlop suggests this will involve an entire restructuring of the economy and culture (and via this of life, of feeling). The example that provokes Dunlop here is Amazon Go, amazon's new material stores in which machine learning, computer vision and AI allow the stores to know (literally to feel out, to grasp) exactly who is shopping and what they pull off the shelves (and of course, via networks, link into their bank accounts). Thus consumers can just grab things and go-with no cashiers (Amazon 2016). As Jordan Pearson points out, what is at stake here is not just the efficiency of job cuts. More than this, Amazon wants to build a 'a closedloop system of integrated consumer surveillance' which 'comes down to knowing you' (2016). Even more than surveilling and 'knowing you', however, Amazon Go is bringing behaviours, thoughts, and feelings into these loops. It's about control of the very power to affect and be affectedin the becoming-environmental of power.

A short speculation on the tendencies that could take this into the future is possible. When I told a friend about this on Facebook, she was somewhat dismayed. I joked, 'don't worry, all the people you see in Amazon's demonstration video are really robots, not humans'. Yet then it hit me. Why wouldn't Capital replace people with AI/robotic networks of simulated consumers, by-passing the need for human consumers as well as workers? My hopefully only speculative reading of the way this is tending is as follows. Imagine indeed replacing the customers with robots spiced up with perhaps even "bespoke" AI to vary their responses. This would revolutionise Friedrich Hayek's sensory order, and revivify what is today his faltering (mis)interpretation of Adam Smith's "invisible hand" as the basis for an economic order of the market. It would fulfil differently the collective sensory order of thinking-feeling, needed for the supposed

${ }^{12}$ See also Murphie 2014. 
optimal functioning of the "invisible hand". In short, it would by-pass the human in market processes. Indeed, this has been beginning to happen for some time in other areas. For example, there is dividualised data (that, synthetic data, made to serve the needs of the system and removed from the actual life of the individual). Another example is the way in which people have become much less significant in much network-based hifrequency financial trading. A particularly telling third example is found in AI now writing its own software (including further AI software), and its own cryptography. There is also an 'AI-run hedge fund' that 'has created a cryptocurrency for its human data' (Faiffe, 2017). Meanwhile, the 'world's largest hedge fund is building an algorithmic model from its employees' brains' (Copeland and Hope, 2016). It is not enough therefore to think about bureaucrats and experts, as well as shop assistants, being replaced by basic interface design, robots, or AI. More is happening. It is true that the Amazon Go store as it is now forms a bridge to the use of much more fine tuned data with which to enclose the very micro-modes of life, the networked fielding/feeling out of the consumers' fielding/feeling. But this in turn might be the basis for a second bridge. This bridge would lead to a world in which the like of AI replaces the human consumer, in fact, most humans or aspects of the human. It is perhaps necessary then to consider AI and robotics as a potential basis for an entirely simulated market, with simulated labour, simulated consumption, simulated Capital, or perhaps even simulated 'something worse than Capital'. Baudrillard was right. All this of course runs on simulated feeling, which is no less real for that (Baudrillard was less right about the unreality of simulation). All this would be the ultimate dream of the $.01 \%$. Total control of every aspect of a simulated economy would fund a way into retreats into protected enclaves, trying to escape the dangers of climate change and other aspects of catastrophic multiplicity.

This has implications for education, and for research, for fields and disciplines, for what these fields and disciplines cover, and for how they cover it, and indeed for the fundamental forms of organisation via which all this happens. Shall we, for example, have an unfortunate choice between something like an "Amazon Go" education increasingly removed from the province of the human. Learning and other analytics would allow AI to tailor automated learning experiences for those learning, draw from a database of alterable lecture fragments, exercises and tests and at the same time pull these experiences and their potentials into the closed loops of certain educational or part-educational conglomerates (perhaps Amazon itself, or a merger of Amazon and Pearson, the education conglomerate currently edging itself into all aspects of education, including AI based education, from testing to curriculum, from school to tertiary education). Or perhaps education would become a matter, via extended machine learning, of machines learning from machines, of data learning from data, and networks learning among themselves? What will humans do? 
Such a remaking of labour, consumption and more would also be a reorganising of what passes for "life", and for whom. It would reorganise much of feeling as the basis for life. Its possibility brings up urgent political-cultural questions that are however too easy displaced towards a disposition against other forms of life in the worst kinds of prejudice and violence.

\section{Data and Feeling}

As I suggested above, throughout all this data can be understood as potentials for feeling. Working with data is therefore a matter of feeling. Moreover, every event, every move in this creates more data as potential for further feeling. A proliferation of data, at an increasingly number of scales, necessarily implies a proliferation of potentials for feeling. Looked at from this angle, catastrophic multiplicity is a massive and pervasive proliferation of data, and thus of potentials for feeling. What will fielding and feeling become when extreme and rapid change leads to greater excesses of potentials for feeling-machine feeling, human feeling, animal feeling and plant feeling, and more, and in-between all these? What will the relation be between all the different intelligences and the many kinds of feeling that are at the moving heart of these intelligences? What will it be to be affected by others or the world, or to affect others or the world? What indeed will words such as "others" and "world", "I" and "we" mean? What does this tell us about feeling in general?

Not only is there an obligation to imagine much about feeling and living differently, there is an urgent necessity to do so, once we have looked the situation in the non-face (while it looks into our faces more and more).

\section{Non/Post/Para/Infra-Institutionalities, and "Studies"}

This is all now the stuff of Media Studies and Cultural Studies and more in the academy, or it should be. Yet institutionality of all kinds is threatened by such events (by economic and climatic disruption, social and political change, and not least by the third media revolution). Will there still be anything resembling universities in five to ten years time, let alone established fields such as Media and Cultural Studies (and every other kind of Studies)? At the same time, questioning institutionality in the light of catastrophic multiplicity reminds us that we do not yet know what Media and Cultural Studies (or other Studies, or any other institutionality) can do, or could become. More generally, we do not know ${ }^{13}$ everything there is to know about what thinking with affect can do, despite the great deal of fine work done in the area.

One useful way to think more freely about such questions-even and especially under the duress of the times-lies in engaging more with what

${ }^{13}$ Here I echo one of Erin Manning's useful refrains. 
Moten and Harney call 'study' (2013: 58ff). Indeed, something like study in this sense seems the lifeblood of engaged intellectual life and of the protection of valuable social life now.

... study is what you do with other people. It's talking and walking around with other people, working, dancing, suffering, some irreducible convergence of all three, held under the name of speculative practice. (Moten and Harney, 2013: 110)

Study moves with fielding and feeling differently, without the calls to order (125) that disciplinarity and institutional "legitimation" bring with them. Yet in doing so, study allows engagement with more important questions-felt questions, lived questions, questions in the midst of change- than institutional legitimation allows. Study challenges the becomingenvironmental of power. Study is also fluid in its relations to non/post/para or what we might call infra-institutional practice. The feeling/fielding of study can involve any of these, from a simple departure from institutions to infra-inhabitation of them. The latter-'infra'-means inhabiting given conditions with a feeling that re-conditions the life involved from within. It is a purposefully restricted use of Massumi's use of 'infra' (to describe affect as 'the infra-conditioning of every determinate activity' ${ }^{14}$ ). Yet study does not need to belong to institutionality. It does not need not to belong. It can inhabit it, or not, or both. It is more concerned with thinking-feeling and in the end has more in common with an active engagement with fiction, film, and music, along with 'walking ... dancing', in so far as these are an active part of social life (all of these seem to me to be better at dealing with the current catastrophic multiplicity than much of the academy). In this it opens up the way that affect or feeling in general can belong to the orders of the times, or not, or both. Study does not need to involve a total refit of the world. It can just as easily involve something approaching Manning's 'minor gesture', 'claiming not space as such, but space-of-variation' (Manning, 2016: 2). As Moten says about the classroom [although this applies to so many other situations]:

... let's just see what happens if I don't make that gesture of calling the class to order - just that little moment in which my tone of voice turns and becomes slightly more authoritative so that everyone will know that class has begun. What if I just say, 'well, we're here. Here we are now.' (126)

Here is a simple tactic-or a propositional feeling - to forego, in situ, destructive propositional feelings that take the form of calls to order. Instead, in study-despite if still sometimes within institutionality-we find

14 'Affect is the infra-conditioning of every determinate activity, including that of language. The preferred prefix for affect is 'infra-'. 'Pre-' connotes time sequence. But affect always accompa- nies, on the parallel track of potential' (2015b: 212). 
that we do not know where things might go, or what even institutionality could become, if only for a moment.

We also find once again that we do not really know, in absolute or finished terms, what feeling itself is doing, within the like of climate change, the third media revolution or social change, and even and especially as we find ourselves new collectivities (human and not) of affecting and being affected. We find, as Glissant writes, that 'Relation is not lived absolutely (it would deny itself), it is felt in reality' (2010: 17). We do not know what feeling could become in the future. We could never absolutely know. Feeling, as process, is both the becoming of the future and of feeling itself. Thus we do not know what life could become, or what the potentials there are even within catastrophic multiplicity for life. Regarding institutions, this means there is a more urgent series of questions involved than the perennials-what should Cultural Studies be, and how should it be delimited, or what, for that matter, should affect theory be or include/exclude? The latter are the traditional disciplinary questions, asked just as much by the interdisciplinary (because it has less institutional traction and therefore must constantly constitute itself). If it's now a time when it's "all hands on deck" (or in fact on quite a few decks at the same time), then perhaps study provides a beginning for the work involved. It needs to happen undetermined by calls to order, unburdened by fear of the loss of the given institutional object (Berlant 2016), and in rejection of the lure for feeling of institutional traction. It certainly needs to abandon defensive propositional feelings, especially when these only exacerbate injustice. There are so many things to let go of in order to enable work with feeling in the folding of multiple catastrophes.

\section{References}

Amazon (2016) 'Introducing Amazon Go and the world's most advanced shopping technology', YouTube.com, December 5, https://www.youtube.com/watch?v=NrmMklMyrxc

Bains, Paul (2002) 'Subjectless Subjectivities', in Massumi, Brian (ed.) A Shock to Thought New York: Routledge: 101-116

Bell, Alice (2016) 'Why we're all everyday climate change deniers', The Guardian, December 6, https://www.theguardian.com/commentisfree/2016/dec/06/trump-worldclimate-change-denial

Berlant, Lauren (2016) 'Interview with Lauren Berlant', IPAK Centar, YouTube.com, https://m.youtube.com/watch?v=lh4rkMSjmjs

Copeland, Rob and Hope, Bradley (2016) 'The World's Largest Hedge Fund Is Building an Algorithmic Model From its Employees' Brains', The Wall Street Journal, http://www.wsj.com/articles/the-worlds-largest- 
hedge-fund-is-building-an-algorithmic-model-of-its-founders-brain1482423694

Da Silva, Denise Ferreira (2007) Toward a Global Idea of Race Minneapolis: University of Minnesota Press

Dejours, Christoph (2007) 'Subjectivity, Work, and Action' in Recognition, Work, Politics: New Directions in French Critical Theory, (eds.) J-P. Deranty, D. Petherbridge, J. F. Rundell, \& R. Sinnerbrink. Brill, Leiden: 71-88

Doyle, Briohny (2016) The Island Will Sink Melbourne: The Lifted Brow

Dunlop, Tim (2016) 'Amazon Go means more than just job losses, it will restructure the economy', The Guardian, July 8, https://www.theguardian.com/sustainablebusiness/2016/dec/09/amazon-go-means-more-than-just-job-losses-it-willrestructure-the-economy

Dupuy, Jean-Pierre (2000) The Mechanization of the Mind: On the Origins of Cognitive Science Princeton: Princeton University Press

Edwards, Paul N. (2010) A Vast Machine Cambridge, MA: MIT Press

Eisenstein, Elizabeth (1979) The Printing Press as an Agent of Change:

Communications and Cultural Transformations in Early-Modern Europe New York: Cambridge University Press

Faiffe, Corin (2017) 'An AI-Run Hedge Fund Has Created a Cryptocurrency for its Human Data Scientists', Motherboard.com, February 23, https://motherboard.vice.com/en_us/article/an-ai-run-hedge-fund-hascreated-a-cryptocurrency-for-its-human-data-

scientists?utm_source=mbtwitter

Glissant, Édouard (2010) Poetics of Relation Lebanon, NH: University of Michigan Press

Guattari, Félix (1995) Chaosmosis: An Ethico-Aesthetic Paradigm Bloomington: Indiana University Press

Haraway, Donna (2016) Staying with the Trouble: Making Kin in the Chthulucene Durham: Duke University Press

Incropera, Frank (2016) Climate Change: A Wicked Problem Cambridge: Cambridge University Press

Klein, Naomi (2007) The Shock Doctrine: The rise of disaster capitalism New York: Metropolitan books 
Manning, Erin (2013) Always More Than One: Individuation's Dance Durham: Duke University Press

Manning, Erin (2016) The Minor Gesture Durham: Duke University Press

Manning, Erin, Massumi, Brian, Fritsch, Jonas and Stavning Thomsen, Bodil Marie (2012) 'Affective Attunement in a Field of Catastrophe', Peripeti, http://www.peripeti.dk/2012/06/06/affective-attunement-in-a-field-ofcatastrophe/

Massumi, Brian and Zournazi, Mary (2002) 'Navigating Movements: An Interview with Brian Massumi' in Mary Zournazi (ed.) Hope: new philosophies for change Sydney: Pluto: 210-242

Massumi, Brian (2002) Parables for the Virtual Durham; Duke University Press

Massumi (2008) 'The Thinking-Feeling of What Happens: A Semblance of a Conversation', Inflexions l(1):

http://www.senselab.ca/inflexions/htm/node/Massumi.html

Massumi, Brian (2015a) Ontopower: War, Powers and the State of Perception Durham: Duke University Press

Massumi, Brian (2015b) Politics of Affect Cambridge: Polity

Massumi, Brian (2017) 'Virtual Ecology and the Question of Value' in Erich Hörl and James Edward Burton (eds.) General Ecology: The New Ecological Paradigm London: Bloomsbury Press: 345-375

Moore, Jason W. (2015) Capitalism in the Web of Life: Ecology and the Accumulation of Capital, London: Verso

Moten, Fred and Harney, Stefano (2013) The Undercommons New York: Minor Compositions

Moten, Fred (2015a) 'Blackness and Poetry', YouTube.com, March 19, https://www.youtube.com/watch?v=Su7iCumqLvo

Moten, Fred (2015b) 'Blackness and Poetry', Evening Will Come: A Monthly Journal of Poetics, 55(July): http://www.thevolta.org/ewc55-fmoten-pl.html

Murphie, Andrew (2011) 'On Not Performing: the third enclosure and fractal neofeudal fantasies', Scan, 8(1):

http://scan.net.au/scn/journal/vol8number l/Andrew-Murphie.html

Murphie, Andrew (2014) 'Auditland', PORTAL Journal of Multidisciplinary International Studies, 1 l(2), http://dx.doi.org/10.5130/portal.vl li2.3407 
Murphie, Andrew (2017) 'The World as Medium' in Manning, Erin, Munster, Anna and Stavning Thomsen, Bodil Marie (eds.) Immediations Sydney: Open Humanities Press

Pasquinelli, Matteo (ed.) (2015) Alleys of Your Mind: Augmented Intelligence and Its Traumas Leuphana: Meson Press

Pasquinelli, Matteo (2016) 'On carbosilicon assemblages and cyberfossil capital', matteopasquinelli.com, http://matteopasquinelli.com/studiumgenerale-rietveld-academie/

Pearson, Jordan (2016) 'Amazon Isn't Trying to Kill Cashier Jobs, It's After Something Bigger', Motherboard.com, December 7, https://motherboard.vice.com/en_us/article/amazon-go-isnt-trying-to-killcashier-jobs-its-after-something-bigger

Povinelli, Elizabeth, Coleman, Mat, and Yusoff, Kathryn (2016) 'Interview with Elizabeth Povinelli by Mat Coleman and Kathryn Yusoff', Society and Space, July 18, http://societyandspace.com/2014/03/06/interview-withelizabeth-povinelli-with-mat-coleman-and-kathryn-yusoff/

Rifkin, Jeremy (2011) The Third Industrial Revolution: How Lateral Power is Transforming Energy, the Economy, and the World New York: Palgrave Macmillan

Schwab, Klaus (2016) 'The Fourth Industrial Revolution: what it means, how to respond', weforum.org,

https://www.weforum.org/en/agenda/archive/fourth-industrial-revolution

Slack, Jennifer Daryl (2006) 'Communication as Articulation' in Gregory J.Shepherd, Jeffrey St.John and Ted Striphas (eds.) Communication as ...: Perspectives on Theory London: Sage: 223-231

Wark, McKenzie (2017) 'What if this is not Capitalism Any More, but Something Worse? NPS Plenary Lecture, APSA 2015, Philadelphia, PA', New Political Science 39(1): 58-66

Whitehead, Alfred North (1920) The Concept of Nature Cambridge: Cambridge University Press

Whitehead, Alfred North (1978) Process and Reality New York: The Free Press 